\title{
Probing Subsistence of Host Guest Inclusion Complexes of Oligosaccharides with Allopurinol for Regulatory Release with the Manifestation of Solvation Consequences
}

\author{
Jaygopal Mondal ${ }^{1}$, Ashutosh Dutta ${ }^{1}$, Koyeli Das ${ }^{1}$, Debasmita Das ${ }^{1}$, Paramita Karmakar ${ }^{1}$, Swarnab Sengupta ${ }^{2}$, \\ Arindam Bhattacharya ${ }^{2}$, Rajesh Kumar Das ${ }^{1}$, Mahendra Nath Roy ${ }^{1, *}$
}

${ }^{1}$ Department of Chemistry, University of North Bengal, Darjeeling - 734 013, West Bengal, India.

${ }^{2}$ Department of Micro-Biology, University of North Bengal, Darjeeling - 734 013, West Bengal, India.

\section{ART ICLE DETAILS}

Article history:

Received 09 February 2019

Accepted 01 March 2019

Available online 05 May 2019

Keywords:

Allopurinol

Host-Guest Inclusion Complex

Thermophysical Property

\section{A B S T R A C T}

The inspection of molecular interaction widespread in allopurinol and in aqueous solutions of $\alpha$-, $\beta$ - and HP- $\beta$-cyclodextrin have been probed by thermophysical properties. The established complexes obtained with 1:1 stoichiometry. Role of solvent (aqueous solution of $\alpha-C D, \beta-C D, H P-\beta-C D$ ) and contribution of solute-solute and solute-solvent interactions to solution complexes, have also been analyzed via stability constant-NMR, UV, steady state fluorescence, FTIR, HRMS, SEM, PXRD, cytotoxicity, hydrophobic effect, hydrogen-bonding, structural effects in creation of inclusion complexes.

\section{Introduction}

Uric acid is end-product of the purine catabolic path. Enzyme xanthine oxido reductase is concerned in formation of uric acid from hypoxanthine and xanthine. Xanthine oxidoreductase exists in two distinct functional forms including xanthine dehydrogenase and xanthine oxidase [1-7]. Allopurinol or 1,5-dihydro-4H-pyrazolo [3,4-d] pyrimidin-4-one, is a purine inhibitor of the enzyme xanthine oxidase. This material as a significant drug for hyperuricemia can inhibit the synthesis of uric acid [811]. Ever in the last 50 years ago, it has been administered for treatment of gout. In the year of 1946, allopurinol was developed by Elion and colleagues, at Burroughs-Wellcome Company. Allopurinol (ALP) is quickly oxidized by xanthine oxidase to hypoxanthine and xanthine, respectively. ALP after oral administration is rapidly absorbed and has a short half-life in plasma (about 2-3 hours). Therefore, we have used all the supramolecular molecules with various cavity sizes to show its controlled release and increase its longevity in the plasma. Xanthine oxidase is a noteworthy biological source of free radical generation and ALP, as an antioxidant, has direct and indirect antioxidant activity on these free radicals. Furthermore, it can scavenge free radicals such as hydroxyl radical and superoxide anion and numerous studies have shown these effects of ALP. This drug revealed advantageous effects in the treatment of some renal disorders both in experimental and clinical trials [12-17].

Macrocyclic cyclodextrins (enzymic conversion products of starch) were exposed in 1891, and structures were elucidated in the mid-1930s. Their industrial implication become obvious in the $1970 \mathrm{~s}$, by now thousands of tons of the three cyclodextrins ( $\alpha-, \beta-$, and HP- $\beta-C D)$ and of their chemical derivatives and inclusion complexes are produced industrially. Outer surface of these doughnut-shaped molecules is hydrophilic, but they have an axial open cavity, which is of hydrophobic character and capable of including other apolar molecules (or their moiety) in case of geometric compatibility. This is the real meaning of molecular encapsulation by inclusion complex formation. Taking into account that one, and probably largest, field of practical utilization of CDs is based on their solubilizing capacity (mainly in pharmaceutical industry) due attention must be paid to the above-mentioned, and many other CDrelated, apparent anomalies by solution chemistry [18-25]
The goal of this paper is to give comprehensive information about therapeutic effects and the controlled delivery of allopurinol as an antioxidant agent in some diseases including hyperuricemia, renal IRI, nephrotoxicity, gout, contrast-induced nephropathy etc.

\section{Experimental Methods}

\subsection{Source and Purity of Materials}

Allopurinol and CD's purchased from Sigma-Aldrich. Mass fractions purity of both was $\geq 0.99$. The used reagents were placed in the desiccators over $\mathrm{P}_{2} \mathrm{O}_{5}$ to keep them in dry atmosphere. These chemicals were used as received without extra purification (Fig. 1)

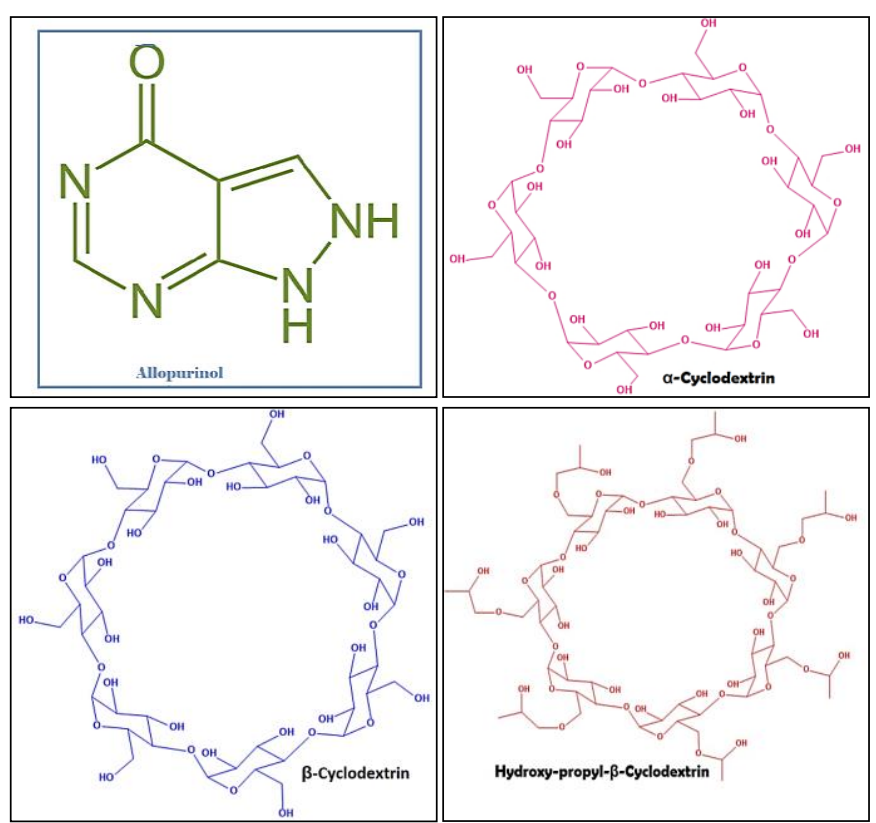

Fig. 1 Molecular structures of the hosts and guest 


\subsection{Apparatus and Procedure}

Prior to start of the experimental work we observed that allopurinol soluble in all proportion of aqueous CD solutions. Therefore, mother solutions of Allopurinol were prepared by mass (Mettler Toledo AG-285 with uncertainty $0.0003 \mathrm{~g}$ ) and then the working solutions were prepared by mass dilution. Conversions of molarity into molality had been done using experimental density values of respective solutions and adequate precautions were taken to reduce evaporation losses during mixing in the experiment.

${ }^{1} \mathrm{H}$ NMR and 2D ROESY spectra of the solid inclusion complex prepared were recorded in $\mathrm{D}_{2} \mathrm{O}$ using Bruker AVANCE $400 \mathrm{MHz}$ instrument. The signals are presented in ppm using residual protonated solvent signal at $4.79 \mathrm{ppm}$ in $\mathrm{D}_{2} \mathrm{O}$ as internal standard and all the Data are reported as chemical shift. UV-visible spectroscopic data was carried out using JASCO V-530 UV/VIS Spectro-photometer with wavelength accuracy of $\pm 0.5 \mathrm{~nm}$. Spectra were recorded at $(297.15 \pm 1)$ K. FTIR spectras of solid ICs were recorded by Perkin Elmer FT-IR Spectrometer using $\mathrm{KBr}$ desk procedure with scanning range of 200 to $4000 \mathrm{~cm}^{-1}$. Mass spectroscopic study was taken by JEOL GC MATE II quadruple double focusing mass analyser using electron impact ionization.

\subsection{Preparation of Solid Inclusion Complex}

Preparations of solid inclusion complex $1.34 \mathrm{~g}$ of CD's were dissolved in $30 \mathrm{~mL}$ of triply distilled and degassed water in round bottom flasks. Mixture was stirred to make homogeneous solutions over magnetic stirrer. Alternatively, solutions of [ALP] was prepared taking $0.295 \mathrm{~g}$ of [ALP] in a separate beaker with $15 \mathrm{~mL}$ water and stirred until homogeneous mixtures were formed. Subsequent to both the homogeneous mixtures are prepared, the ALP solution was then added into CD solution slowly with continuous stirring and after completion of the addition the ALP solution the mixture was stirred for $48 \mathrm{~h}$ continuously.

Following completion of 48 hours, mixture was allowed to cool at lower temperature when a white solid was observed. Then the precipitate was filtered and washed for several times. Lastly, the dry white powder was obtained after drying in oven at $50^{\circ} \mathrm{C}$ for $24 \mathrm{~h}$. The solid inclusion complex with all CD's was prepared following the same procedure. The resulting solids of inclusion complex between ALP and CD were found to dissolve in pure distilled water freely. These solids were further analyzed and characterized by means of FTIR, UV-VIS, NMR and ESI-Mass spectroscopic methods.

\section{Results and Discussion}

\subsection{JOB Plot}

Job's continuous variation method was applied to determine stoichiometry of the inclusion complexes formed. By the measurement of absorbance of a set of solutions prepared of the ALP and CD in water mixture in the mole fraction range of 0-1 (Tables 1-3). Here we calculate $(\Delta \mathrm{A} \times \mathrm{R})$ values against $\mathrm{R}$, where $\Delta \mathrm{A}$ signifies the difference in absorbance of ALP in the pure form and complexed form and R is [ALP]/ ([ALP] + [CD]).

$\lambda_{\max }$ was found at $250 \mathrm{~nm}$ at $298.15 \mathrm{~K}$. Ratio of guest and host i.e., stoichiometry is obtained from value of $\mathrm{R}$ at maxima on the Job' Plot such as $\mathrm{R} \approx 0.33$, for $1: 2$ IC, $\mathrm{R} \approx 0.5$ for $1: 1$ IC, $\mathrm{R} \approx 0.66$ for $2: 1$ IC etc. In the experiment of ALP and CD's the maxima in the Job' plots were obtained at $\mathrm{R} \approx 0.5$ which is the indication of $1: 1$ stoichiometry of ALP and CD ICs (Figs. 2a-c) [26-29].

Table 1 Data of Job's plot between ALP and $\alpha$-CD obtained from UV spectroscopy

\begin{tabular}{llllllll}
\hline $\begin{array}{l}\text { ALP } \\
(\mathrm{mL})\end{array}$ & $\begin{array}{l}\alpha-\mathrm{CD} \\
(\mathrm{mL})\end{array}$ & $\begin{array}{l}\text { ALP } \\
(\mu \mathrm{M})\end{array}$ & $\begin{array}{l}\alpha-\mathrm{CD} \\
(\mu \mathrm{M})\end{array}$ & $\begin{array}{l}{[\mathrm{ALP}] /} \\
([\mathrm{ALP}]+ \\
[\alpha \mathrm{CD}])\end{array}$ & $\begin{array}{l}\text { ABSORB } \\
\text { ANCE }\end{array}$ & $\Delta \mathrm{A}$ & $\begin{array}{l}\Delta \mathrm{A}^{*}[\mathrm{AL} \\
\mathrm{P}] / \\
([\mathrm{ALP}]+ \\
[\alpha \mathrm{CD}])\end{array}$ \\
\hline 4 & 0 & 100 & 0 & 1 & 3.543 & 0 & 0 \\
3.6 & 0.4 & 90 & 10 & 0.9 & 3.743 & 0.2 & 0.18 \\
3.2 & 0.8 & 80 & 20 & 0.8 & 3.416 & 0.327 & 0.2616 \\
2.8 & 1.2 & 70 & 30 & 0.7 & 3.416 & 0 & 0 \\
2.4 & 1.6 & 60 & 40 & 0.6 & 2.909 & 0.507 & 0.3042 \\
2 & 2 & 50 & 50 & 0.5 & 2.563 & 0.346 & 0.173 \\
1.6 & 2.4 & 40 & 60 & 0.4 & 2.133 & 0.43 & 0.172 \\
1.2 & 2.8 & 30 & 70 & 0.3 & 1.783 & 0.35 & 0.105 \\
0.8 & 3.2 & 20 & 80 & 0.2 & 1.272 & 0.511 & 0.1022 \\
0.4 & 3.6 & 10 & 90 & 0.1 & 0.877 & 0.395 & 0.0395 \\
0 & 4 & 0 & 100 & 0 & 0.299 & 0.578 & 0 \\
\hline
\end{tabular}

https://doi.org/10.30799/jacs.205.19050105

Cite this Article as: Jaygopal Mondal, Ashutosh Dutta, Koyeli Das, Debasmita Das, Paramita Karmakar, et al., Probing subsistence of host guest inclusion complexes of oligosaccharides with allopurinol for regulatory release with the manifestation of solvation consequences, J. Adv. Chem. Sci. 5(1) (2019) 621-628.
Table 2 Data of Job's plot between ALP and $\beta$-CD obtained from UV spectroscopy

\begin{tabular}{|c|c|c|c|c|c|c|c|}
\hline $\begin{array}{l}\mathrm{ALP} \\
(\mathrm{mL})\end{array}$ & $\begin{array}{l}\beta-\mathrm{CD} \\
(\mathrm{mL})\end{array}$ & $\begin{array}{l}\text { ALP } \\
(\mu \mathrm{M})\end{array}$ & $\begin{array}{l}\beta-C D \\
(\mu \mathrm{M})\end{array}$ & $\begin{array}{l}{[\mathrm{ALP}] /([} \\
\mathrm{ALP}]+[\beta \\
\mathrm{CD}])\end{array}$ & $\begin{array}{l}\text { ABSORB } \\
\text { ANCE }\end{array}$ & $\Delta \mathrm{A}$ & $\begin{array}{l}\Delta \mathrm{A}^{*}[\mathrm{AL} \\
\mathrm{P}] /([\mathrm{AL} \\
\mathrm{P}]+[\beta- \\
\mathrm{CD}])\end{array}$ \\
\hline 4 & 0 & 100 & 0 & 1 & 3.997 & 0.324 & 1.345 \\
\hline 3.6 & 0.4 & 90 & 10 & 0.9 & 3.998 & 0.456 & 1.461 \\
\hline 3.2 & 0.8 & 80 & 20 & 0.8 & 3.999 & 0.567 & 1.562 \\
\hline 2.8 & 1.2 & 70 & 30 & 0.7 & 3.999 & 0.782 & 1.721 \\
\hline 2.4 & 1.6 & 60 & 40 & 0.6 & 3.096 & 0.903 & 2.503 \\
\hline 2 & 2 & 50 & 50 & 0.5 & 2.588 & 0.508 & 2.508 \\
\hline 1.6 & 2.4 & 40 & 60 & 0.4 & 2.302 & 0.286 & 2.686 \\
\hline 1.2 & 2.8 & 30 & 70 & 0.3 & 1.73 & 0.572 & 3.372 \\
\hline 0.8 & 3.2 & 20 & 80 & 0.2 & 0.821 & 0.909 & 4.109 \\
\hline 0.4 & 3.6 & 10 & 90 & 0.1 & 0.778 & 0.043 & 3.643 \\
\hline 0 & 4 & 0 & 100 & 0 & 0.417 & 0.361 & 3.175 \\
\hline
\end{tabular}

Table 3 Data of Job's plot between ALP and HP- $\beta$-CD obtained from UV spectroscopy

\begin{tabular}{llllllll}
\hline $\begin{array}{l}\text { ALP } \\
(\mathrm{mL})\end{array}$ & $\begin{array}{l}\text { HP- } \beta \text {-CD } \\
(\mathrm{mL})\end{array}$ & $\begin{array}{l}\text { ALP } \\
(\mu \mathrm{M})\end{array}$ & $\begin{array}{l}\text { HP- } \beta-\mathrm{CD} \\
(\mu \mathrm{M})\end{array}$ & $\begin{array}{l}{[\mathrm{ALP}] /} \\
([\mathrm{ALP}]+ \\
{[\mathrm{HP}-\beta-}\end{array}$ & $\begin{array}{l}\text { ABSORB } \\
\text { ANCE }\end{array}$ & $\begin{array}{l}\Delta \mathrm{A} \\
\mathrm{CD}])\end{array}$ & $\begin{array}{l}\Delta \mathrm{A}^{*}[\mathrm{AL} \\
\mathrm{P}] / \\
([\mathrm{ALP}]+\end{array}$ \\
\hline 4 & 0 & 100 & 0 & 1 & 3.573 & 0 & 0 \\
3.6 & 0.4 & 90 & 10 & 0.9 & 3.959 & 0.386 & 10.386 \\
3.2 & 0.8 & 80 & 20 & 0.8 & 3.965 & 0.006 & 20.006 \\
2.8 & 1.2 & 70 & 30 & 0.7 & 3.999 & 0.034 & 30.034 \\
2.4 & 1.6 & 60 & 40 & 0.6 & 3.337 & 0.662 & 39.338 \\
2 & 2 & 50 & 50 & 0.5 & 1.844 & 1.493 & 48.507 \\
1.6 & 2.4 & 40 & 60 & 0.4 & 1.435 & 0.409 & 59.591 \\
1.2 & 2.8 & 30 & 70 & 0.3 & 1.225 & 0.21 & 69.79 \\
0.8 & 3.2 & 20 & 80 & 0.2 & 0.959 & 0.266 & 79.734 \\
0.4 & 3.6 & 10 & 90 & 0.1 & 0.751 & 0.208 & 89.792 \\
0 & 4 & 0 & 100 & 0 & 0.58 & 0.171 & 0 \\
\hline
\end{tabular}

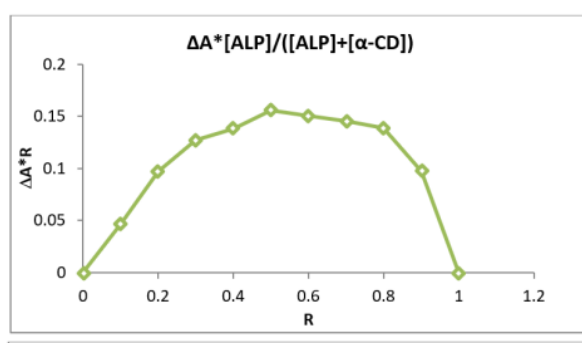

$\Delta \mathrm{A}^{*}[\mathrm{ALP}] /([\mathrm{ALP}]+[\beta-\mathrm{CD}])$

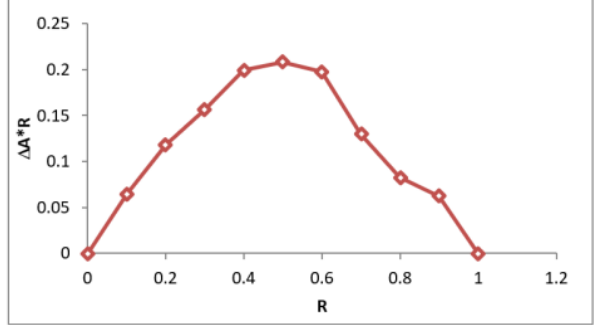

$\Delta A^{*}[A L P] /([A L P]+[H P-\beta-C D])$

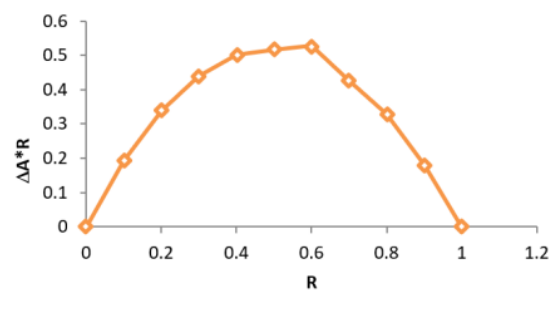

Fig. 2 Job's Plot for [ALP] with a) $\alpha-C D$, b) $\beta-C D$ and c) HP- $\beta$-CD

\subsection{Determination of Binding (or Association) Constant by UV-Vis Spectroscopy}

The binding constant between $\alpha-C D, \beta-C D, H P-\beta-C D$ and ALP has been evaluated via UV-Vis spectroscopy. The Benesi-Hildebrand technique represents one of the most common strategies to determine binding constants based on absorption spectra for inclusion complex. With the help of Benesi-Hildebrand method for 1:1 host-guest ICs, doublereciprocal plots of $1 / \Delta \mathrm{A}$ against $1 /$ [CD] were plotted using the following equation (Figs. 3-5). 

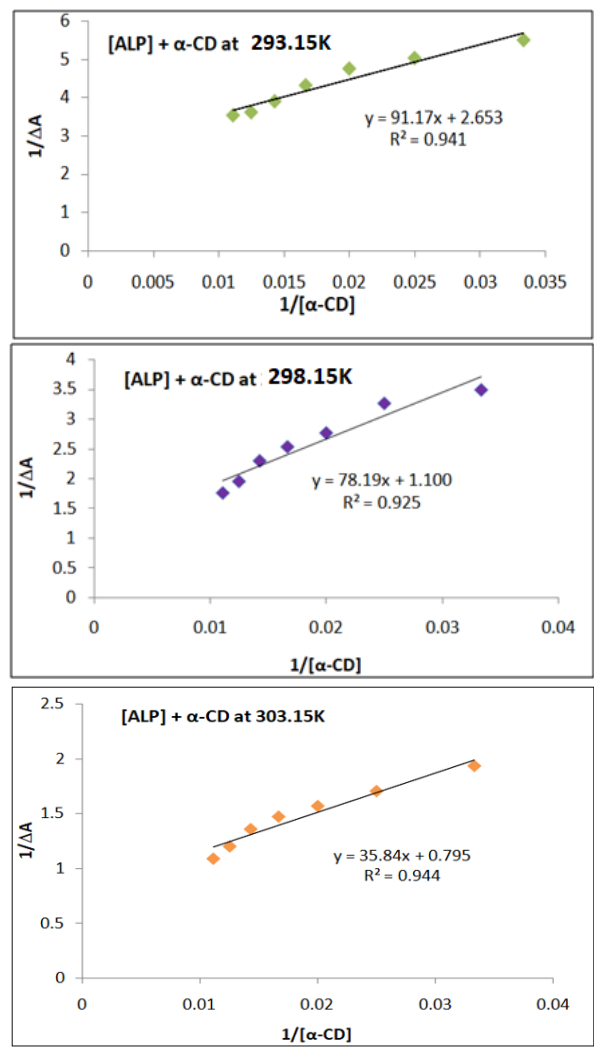

Fig. 3 Benesi-Hildebrand double reciprocal plots for the effect of $\alpha$-CD on the absorbance of [ALP] at a) $293.15 \mathrm{~K}$, b) $298.15 \mathrm{~K}$ and c) $303.15 \mathrm{~K}$
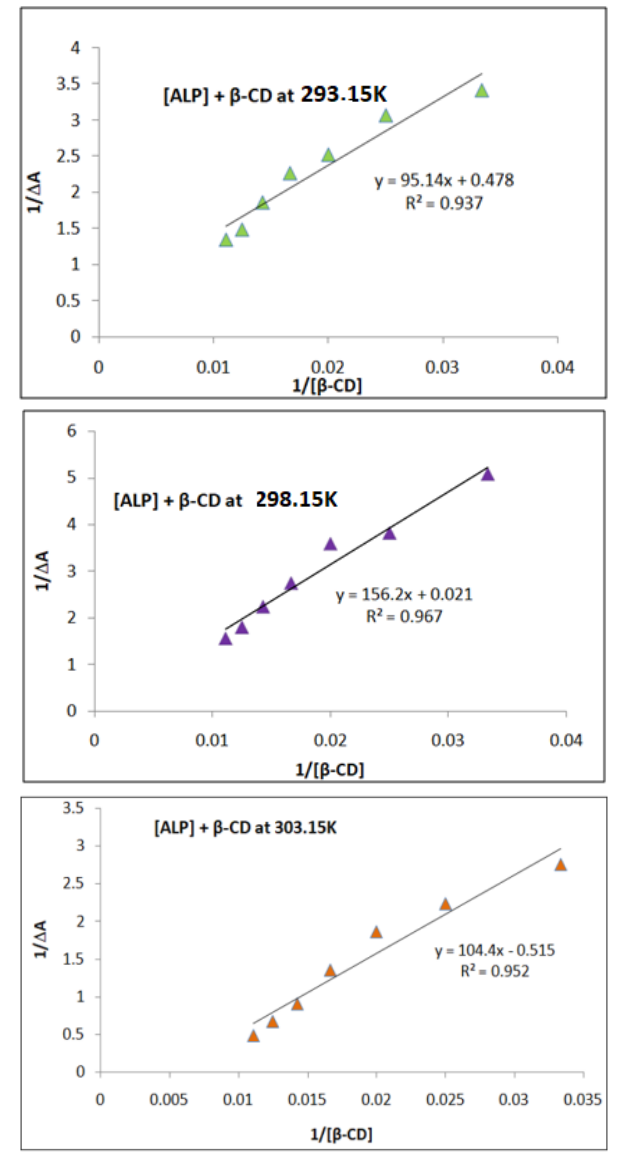

Fig. 4 Benesi-Hildebrand double reciprocal plots for the effect of $\beta$-CD on the absorbance of [ALP] at a) $293.15 \mathrm{~K}$, b) $298.15 \mathrm{~K}$ and c) $303.15 \mathrm{~K}$

$$
\frac{1}{\Delta A}=\frac{1}{\Delta \varepsilon[V] K_{a}} X \frac{1}{[C D]}+\frac{1}{\Delta \varepsilon[V]}
$$

Association constants $\left(\mathrm{K}_{\mathrm{a}}^{\mathrm{c}} \mathrm{c}\right.$ ) were also calculated for the inclusion complexation of ALP and CD by means of conductivity study with the help https://doi.org/10.30799/jacs.205.19050105 of a nonlinear program. Basing upon the fact that the insertion of the ALP inside the CD cavity changes the conductivity of the solutions. The equilibrium between ALP and CD can be represented as:

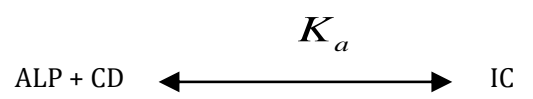

The equilibrium constant, $K_{a}$ is represented as,

$$
\mathrm{K}_{\mathrm{a}}=[\mathrm{IC}] /[\mathrm{ALP}][\mathrm{CD}] * \mathrm{f}(\mathrm{IC}) / \mathrm{f}(\mathrm{ALP}) \mathrm{f}(\mathrm{CD})
$$

where, [IC], [ALP] and [CD] are molar concentrations of inclusion complex, allopurinol and cyclodextrin's at equilibrium accordingly. (f) is activity coefficients of the respective species (Tables 4-6). The activity coefficient of $C D, f(C D)$, can be assumed as unity as system was dilute. In order to have an accurate estimation of binding constants of the inclusion complexes under investigation, changes in the absorption intensity of the ALP at different wavelength, were monitored as a function of the CD's concentration and non-linear regression estimation of the $K_{a}$ was chosen.
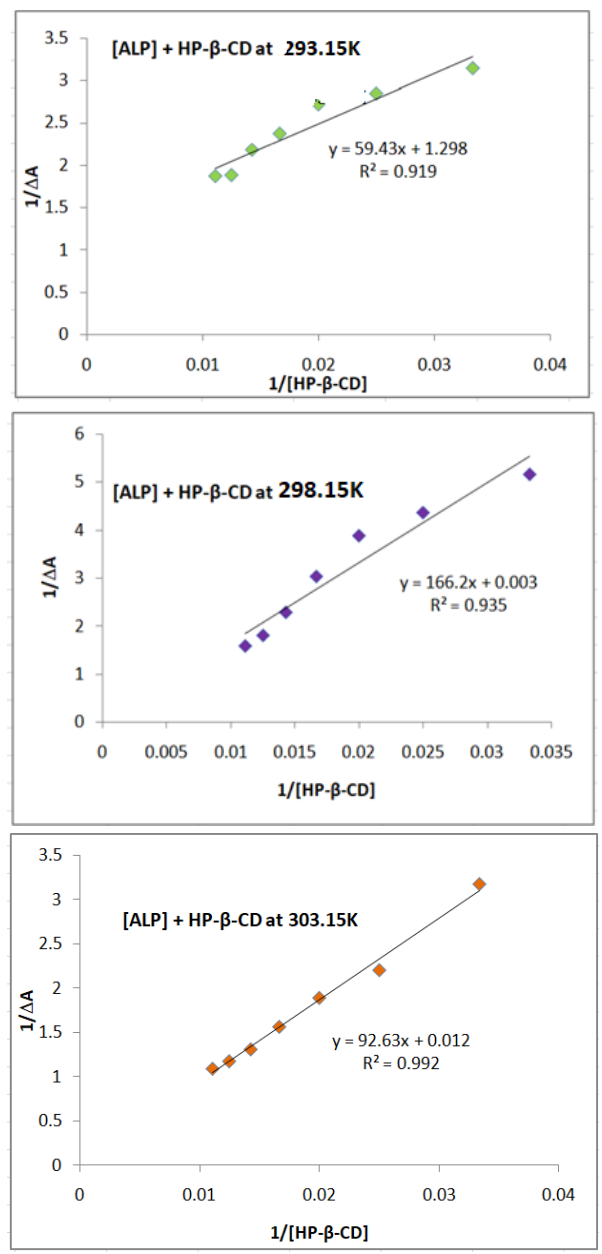

Fig. 5 Benesi-Hildebrand double reciprocal plots for the effect of HP- $\beta$-CD on the absorbance of [ALP] at a) $293.15 \mathrm{~K}$, b) $298.15 \mathrm{~K}$ and c) $303.15 \mathrm{~K}$

Table 4 Data for the Benesi-Hildebrand double reciprocal plot performed by UV-VIS spectroscopic study for [ALP]- $\alpha$-CD systems at $(293.15,298.15$, and 303.15$) \mathrm{K}$

\begin{tabular}{llllllll}
\hline temp/ & {$[\mathrm{ALP}] /$} & {$[\alpha-\mathrm{CD}] /$} & $\mathrm{A}_{\circ}$ & $\mathrm{A}$ & $\Delta \mathrm{A}$ & $\begin{array}{l}1 /[\alpha- \\
\mathrm{CD}] / \mathrm{M}^{-1}\end{array}$ & $1 / \Delta \mathrm{A}$ \\
\hline & $\mu \mathrm{M}$ & $\mu \mathrm{M}$ & & & & 0.03333 & 5.49752 \\
& 50 & 30 & 0.9926 & 1.1745 & 0.1819 & 0.035 & 5.03271 \\
$293.15 \mathrm{~K}$ & 50 & 50 & 0.9926 & 1.2028 & 0.2102 & 0.02 & 4.75737 \\
& 50 & 60 & 0.9926 & 1.2239 & 0.2313 & 0.01667 & 4.32339 \\
& 50 & 70 & 0.9926 & 1.2484 & 0.2558 & 0.01429 & 3.90930 \\
& 50 & 80 & 0.9926 & 1.2684 & 0.2758 & 0.0125 & 3.62582 \\
& 50 & 90 & 0.9926 & 1.2747 & 0.2821 & 0.01111 & 3.54484 \\
$298.15 \mathrm{~K}$ & 50 & 30 & 0.9926 & 1.2789 & 0.2863 & 0.03333 & 3.49284 \\
& 50 & 40 & 0.9926 & 1.2986 & 0.306 & 0.025 & 3.26797 \\
& 50 & 50 & 0.9926 & 1.3535 & 0.3609 & 0.02 & 2.77085 \\
& 50 & 60 & 0.9926 & 1.3867 & 0.3941 & 0.0167 & 2.53743 \\
& 50 & 70 & 0.9926 & 1.4269 & 0.4343 & 0.0142 & 2.30256 \\
\hline
\end{tabular}




\begin{tabular}{rllllll}
\hline 50 & 80 & 0.9926 & 1.5034 & 0.5108 & 0.0125 & 1.95771 \\
50 & 90 & 0.9926 & 1.5594 & 0.5668 & 0.01111 & 1.76429 \\
$303.15 \mathrm{~K} 50$ & 30 & 0.9926 & 1.5096 & 0.517 & 0.03333 & 1.93424 \\
50 & 40 & 0.9926 & 1.5791 & 0.5865 & 0.025 & 1.70503 \\
50 & 50 & 0.9926 & 1.62991 & 0.6373 & 0.02 & 1.56909 \\
50 & 60 & 0.9926 & 1.6715 & 0.6789 & 0.01667 & 1.47297 \\
50 & 70 & 0.9926 & 1.7286 & 0.736 & 0.01429 & 1.35870 \\
50 & 80 & 0.9926 & 1.8247 & 0.8321 & 0.0125 & 1.20178 \\
50 & 90 & 0.9926 & 1.9105 & 0.9179 & 0.01111 & 1.08944 \\
\hline
\end{tabular}

Table 5 Data for the Benesi-Hildebrand double reciprocal plot performed by UV-VIS spectroscopic study for [ALP]- $\beta$-CD systems at $(293.15,298.15$, and 303.15) K

\begin{tabular}{|c|c|c|c|c|c|c|c|}
\hline $\begin{array}{l}\text { temp/ } \\
\mathrm{K}\end{array}$ & $\begin{array}{l}{[\mathrm{ALP}] /} \\
\mu \mathrm{M}\end{array}$ & $\begin{array}{l}{[\beta-C D] /} \\
\mu \mathrm{M}\end{array}$ & $A_{\circ}$ & A & $\Delta \mathrm{A}$ & $\begin{array}{l}1 /\left[\beta^{-}\right. \\
\mathrm{CD}] / \mathrm{M}^{-1}\end{array}$ & $1 / \Delta \mathrm{A}$ \\
\hline & 50 & 30 & 0.9926 & 1.2854 & 0.2928 & 0.03333 & 3.41530 \\
\hline & 50 & 40 & 0.9926 & 1.3185 & 0.3259 & 0.025 & 3.06842 \\
\hline \multirow[t]{5}{*}{$293.15 \mathrm{~K}$} & 50 & 50 & 0.9926 & 1.3883 & 0.3957 & 0.02 & 2.52716 \\
\hline & 50 & 60 & 0.9926 & 1.4331 & 0.4405 & 0.01667 & 2.27015 \\
\hline & 50 & 70 & 0.9926 & 1.5281 & 0.5355 & 0.01428 & 1.86741 \\
\hline & 50 & 80 & 0.9926 & 1.6621 & 0.6695 & 0.0125 & 1.49365 \\
\hline & 50 & 90 & 0.9926 & 1.7315 & 0.7389 & 0.01111 & 1.35336 \\
\hline \multirow[t]{7}{*}{$298.15 \mathrm{~K}$} & 50 & 30 & 0.9926 & 1.1892 & 0.1966 & 0.03333 & 5.08647 \\
\hline & 50 & 40 & 0.9926 & 1.2538 & 0.2612 & 0.025 & 3.82848 \\
\hline & 50 & 50 & 0.9926 & 1.2706 & 0.278 & 0.02 & 3.59712 \\
\hline & 50 & 60 & 0.9926 & 1.3555 & 0.3629 & 0.01667 & 2.75558 \\
\hline & 50 & 70 & 0.9926 & 1.4366 & 0.444 & 0.01428 & 2.25225 \\
\hline & 50 & 80 & 0.9926 & 1.5434 & 0.5508 & 0.0125 & 1.81554 \\
\hline & 50 & 90 & 0.9926 & 1.628 & 0.6354 & 0.01111 & 1.57381 \\
\hline \multirow[t]{7}{*}{$303.15 \mathrm{~K}$} & 50 & 30 & 0.9926 & 1.386 & 0.3934 & 0.03333 & 2.54194 \\
\hline & 50 & 40 & 0.9926 & 1.4405 & 0.4479 & 0.025 & 2.23264 \\
\hline & 50 & 50 & 0.9926 & 1.3297 & 0.3371 & 0.02 & 2.96648 \\
\hline & 50 & 60 & 0.9926 & 1.5344 & 0.5418 & 0.01667 & 1.8457 \\
\hline & 50 & 70 & 0.9926 & 2.0923 & 1.0997 & 0.01428 & 0.90934 \\
\hline & 50 & 80 & 0.9926 & 2.1743 & 1.1817 & 0.0125 & 0.84624 \\
\hline & 50 & 90 & 0.9926 & 2.3721 & 1.3795 & 0.01111 & 0.7249 \\
\hline
\end{tabular}

Table 6 Data for the Benesi-Hildebrand double reciprocal plot performed by UV-VIS spectroscopic study for [ALP]-HP- $\beta$-CD systems at $(293.15,298.15$, and 303.15) K

\begin{tabular}{|c|c|c|c|c|c|c|c|}
\hline $\begin{array}{l}\text { temp/ } \\
\mathrm{K}\end{array}$ & $\begin{array}{l}{[\mathrm{ALP}] / /} \\
\mu \mathrm{M}\end{array}$ & $\begin{array}{l}{[\mathrm{HP}-\beta-} \\
\mathrm{CD}] / \mu \mathrm{M}\end{array}$ & $A_{\circ}$ & A & $\Delta \mathrm{A}$ & $\begin{array}{l}1 /[\mathrm{HP}-\beta- \\
\mathrm{CD}] / \mathrm{M}^{-1}\end{array}$ & $1 / \Delta \mathrm{A}$ \\
\hline & 50 & 30 & 0.9926 & 1.3111 & 0.3185 & 0.03333 & 3.13971 \\
\hline & 50 & 40 & 0.9926 & 1.3448 & 0.3522 & 0.025 & 2.83929 \\
\hline \multirow[t]{5}{*}{$293.15 \mathrm{~K}$} & 50 & 50 & 0.9926 & 1.3612 & 0.3686 & 0.02 & 2.71297 \\
\hline & 50 & 60 & 0.9926 & 1.4141 & 0.4215 & 0.01667 & 2.37248 \\
\hline & 50 & 70 & 0.9926 & 1.4519 & 0.4593 & 0.01428 & 2.17722 \\
\hline & 50 & 80 & 0.9926 & 1.5249 & 0.5323 & 0.0125 & 1.87864 \\
\hline & 50 & 90 & 0.9926 & 1.5283 & 0.5357 & 0.01111 & 1.86671 \\
\hline \multirow[t]{7}{*}{$298.15 \mathrm{~K}$} & 50 & 30 & 0.9926 & 1.1863 & 0.1937 & 0.03333 & 5.16262 \\
\hline & 50 & 40 & 0.9926 & 1.2217 & 0.2291 & 0.025 & 4.36490 \\
\hline & 50 & 50 & 0.9926 & 1.2501 & 0.2575 & 0.02 & 3.88349 \\
\hline & 50 & 60 & 0.9926 & 1.3222 & 0.3296 & 0.01667 & 3.03398 \\
\hline & 50 & 70 & 0.9926 & 1.4299 & 0.4373 & 0.01428 & 2.28676 \\
\hline & 50 & 80 & 0.9926 & 1.5463 & 0.5537 & 0.0125 & 1.80603 \\
\hline & 50 & 90 & 0.9926 & 1.6234 & 0.6308 & 0.01111 & 1.58529 \\
\hline \multirow[t]{7}{*}{$303.15 \mathrm{~K}$} & 50 & 30 & 0.9926 & 1.3078 & 0.3152 & 0.03333 & 3.17259 \\
\hline & 50 & 40 & 0.9926 & 1.4467 & 0.4541 & 0.025 & 2.20216 \\
\hline & 50 & 50 & 0.9926 & 1.5219 & 0.5293 & 0.02 & 1.88929 \\
\hline & 50 & 60 & 0.9926 & 1.6324 & 0.6398 & 0.01667 & 1.56299 \\
\hline & 50 & 70 & 0.9926 & 1.7565 & 0.7639 & 0.01428 & 1.30907 \\
\hline & 50 & 80 & 0.9926 & 1.8435 & 0.8509 & 0.0125 & 1.17522 \\
\hline & 50 & 90 & 0.9926 & 1.91 & 0.9174 & 0.01111 & 1.09003 \\
\hline
\end{tabular}

\subsection{Fluorescence}

Fluorescence was extensively studied for static and dynamic properties of the aggregated system such as the derivatives of the drug. In amphiphile molecules, CD's (quencher) are preferentially solubilized in their core hydrophobic regions. Change in the microenvironment of solution is experienced by (ALP), where the shift in the absorbance is located. Hence is used to aggregate properties in the form of inclusion. Vibronic band spectra endure major perturbation on transferring from non-polar to a polar environment. Fluorescence measurements are used to determine the association and complexation, of studied complex and also in understanding interaction between the host-guest inclusion processes (ICs). Steady-state fluorescence measurements were done at room https://doi.org/10.30799/jacs.205.19050105 temperature. Concentration of solutions used in all the system was approximately up to $10^{-6} \mathrm{moldm}^{-3}$. The lower the florescence intensity more is the binding with CD's, moreover it is found that in the $\alpha-C D$ inclusion with ALP the controlled release of the drug is more prominent ((Figs. 6a-c) [30, 31].

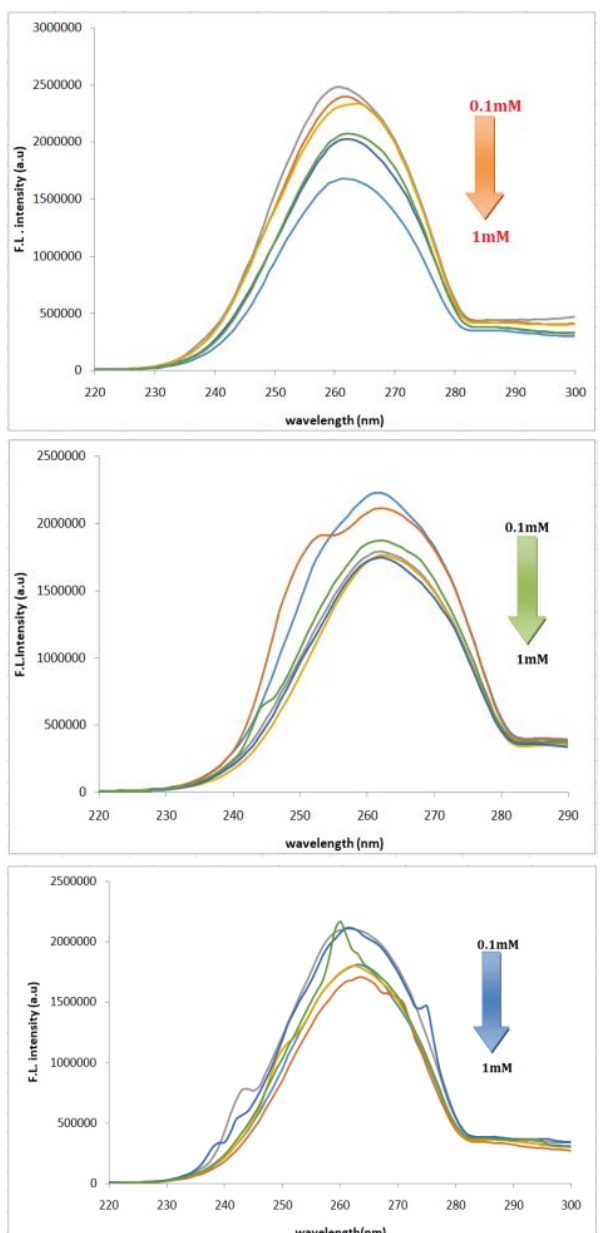

Fig. 6 Fluorescence emission spectrum of aqueous a) $\alpha-C D$, b) $\beta-C D$ and c) HP- $\beta-C D$ in presence of $(0.1 \mathrm{mM}-1.0 \mathrm{mM})$ of ALP $\left(\lambda_{\mathrm{ex}}=250 \mathrm{~nm}\right.$, slit width $\left.=5 / 5\right)$.

\subsection{FTIR Study}

FT-IR study of the solid ICs formed was performed to investigate the formation of the solid ICs. There are changes in frequencies of bands of the inserted guest molecules as well as some bands are absent in the spectra of complex. This may be due to the formation of the ICs. Data for pure compounds and inclusion complexes are recorded and spectroscopic change in wave number before and after inclusion are shown in Figs. 7a-d. Due to non-covalent interactions the changes of bands are observed. In the spectra of $\alpha$-CD, $\beta$-CD and HP- $\beta$-CD the broad bands obtained at $3410 \mathrm{~cm}^{-1}$, $3408 \mathrm{~cm}^{-1}$ and $3415.82 \mathrm{~cm}^{-1}$ are due to the valence vibrations of $-\mathrm{O}-\mathrm{H}$ groups linked by $\mathrm{H}$-bond. The $\mathrm{O}-\mathrm{H}$ stretching for $\alpha-\mathrm{CD}$ and $\beta$-CD obtained at $3410 \mathrm{~cm}^{-1}, 3408 \mathrm{~cm}^{-1}$ and $3415.82 \mathrm{~cm}^{-1}$ were obtained in the complexes $3410.85 \mathrm{~cm}^{-1}, 3415.94 \mathrm{~cm}^{-1}$ and $3414.44 \mathrm{~cm}^{-1}$ respectively, may be due to the interaction of the positively charged nitrogen atom of the pyrazole ring and the oxygen atom of $(\mathrm{C}=0)$ group which is again reflected in the shifted band of $\mathrm{C}=\mathrm{N}$ stretching for $1701.40 \mathrm{~cm}^{-1}$ for the pure ALP to $1601.17 \mathrm{~cm}^{-1}$ in IC of $\alpha-C D, 1623.67 \mathrm{~cm}^{-1}$ in IC of $\beta-C D$ and $1626.80 \mathrm{~cm}^{-1}$ in IC of HP- $\beta$ $\mathrm{CD}$ respectively. The $\mathrm{C}-\mathrm{H}$ stretching and bending are obtained at $2941 \mathrm{~cm}^{-1}$ and $1404 \mathrm{~cm}^{-1}$ for pure $\beta$-CD and $2919.19 \mathrm{~cm}^{-1}$ and $1366.67 \mathrm{~cm}^{-1}$ and HP$\beta$-CD shift is almost the same. For pure $\alpha$-CD, which are shifted in the ICs to $2886.26 \mathrm{~cm}^{-1}$ from $2927 \mathrm{~cm}^{-1}, 1367 \mathrm{~cm}^{-1}$ for $\alpha-C D$. The out of plane $\mathrm{C}-\mathrm{H}$ bending for [ALP] obtained at $814 \mathrm{~cm}^{-1}$ and $768 \mathrm{~cm}^{-1}$ for $\alpha-C D, 761 \mathrm{~cm}^{-1}$ for $\beta-C D$ and $762 \mathrm{~cm}^{-1}$ for HP- $\beta-C D$ respectively. This may be due to the closeness of $\mathrm{C}-\mathrm{H}$ of $\mathrm{CD}$ and the aromatic $\mathrm{C}-\mathrm{H}$ of the ALP. The aromatic stretching bands for pure [ALP] observed at $3165 \mathrm{~cm}^{-1}$, stretching band due to alkyl C-H at $3081 \mathrm{~cm}^{-1}$ and $3042 \mathrm{~cm}^{-1}$, are absent in the spectra of ICs. The peak due to stretching of C-H from $-\mathrm{CH}_{2}-$ at $2941 \mathrm{~cm}^{-1}$ for [ALP] are absent or shifted to $2886 \mathrm{~cm}^{-1}, 2919 \mathrm{~cm}^{-1}$ and $2927 \mathrm{~cm}^{-1}, 2922 \mathrm{~cm}^{-1}$ in the spectra of ICs of $\alpha-C D, \beta-C D$ and HP- $\beta$-CD respectively, may be due to interaction inside the cavity of cyclodextrin. In ICs no additional signal is obtained which deny the chance of chemical reaction. Thus, the study 
provides major information about the formation of the ICs in the solid state [32].
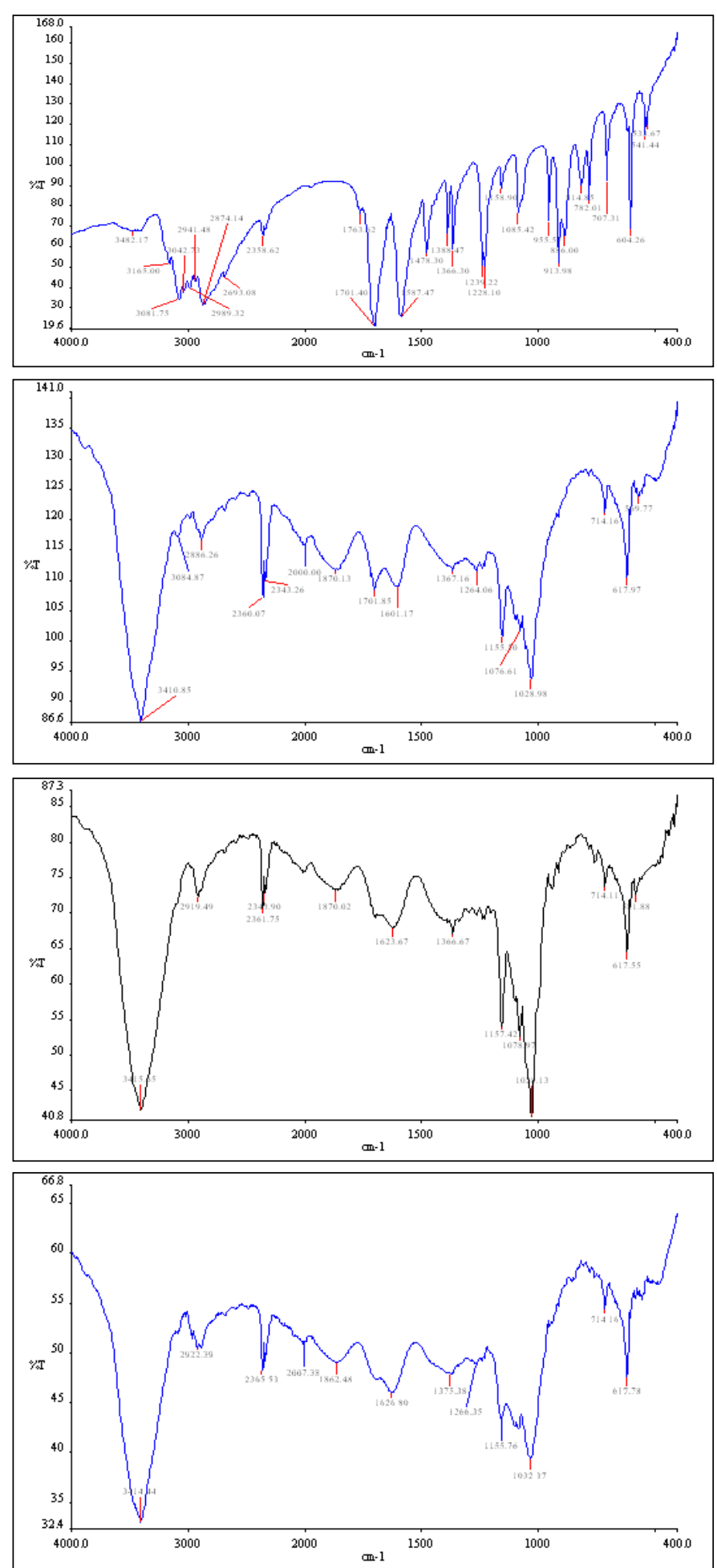

Fig. 7 FT-IR spectra of 1:1 inclusion complexes a) [ALP] +b) [ALP] $+\alpha-C D, c)$ [ALP] $+\beta-C D$ and d) $[$ ALP] + HP- $\beta-C D$ ) at $298.15 \mathrm{~K}$

\section{$3.5^{1} \mathrm{H}$ NMR Spectroscopy}

NMR spectroscopic study in aqueous solution at 298.15 K. Figs. 6a-c represents ${ }^{1} \mathrm{H}$ NMR spectra of the complex of ALP with $\alpha-C D, \beta-C D$ and HP$\beta$-CD which describes slight downfield shift of the aliphatic protons of guest molecule. The signal due to aryl protons are nearly shifted and little broadening. Conversely protons of guest molecules of the aliphatic chain illustrate a slight change in their signals while present in the complex $\alpha, \beta$ and $\gamma$ protons of free ALP appears downfield shift respectively, then complex. This result clearly reveals the existence of some sort of association between the electron rich oxygen atoms of the CD's and the nitrogen atom (Scheme 1). The aromatic part of the ALP shows no change of their signals indicating their free state in the solvent medium.

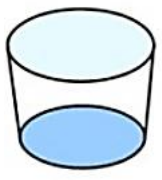

$\mathrm{CD}$

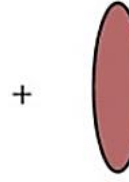

Drug

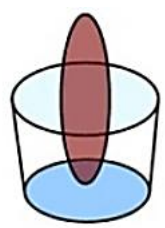

$1: 1$ drug-CD complex
Scheme 1 Diagrammatic representation of the probable complexes obtained

Upon inclusion, upfield chemical shift values $(\Delta \delta)$ of the $\mathrm{H} 3$ and $\mathrm{H} 5$ protons of $\alpha$ and $\beta$-Cyclodextrins and H3 protons for HP- $\beta$-CD have been shown in Fig. 8, which confirm that the interaction of the guest ALP with $\mathrm{H} 3$ is greater than that with $\mathrm{H} 5$, signifying that the inclusion has taken place through the wider rim of the $\alpha, \beta$ and HP- $\beta$-Cyclodextrins.

It is to be mentioned that upon inclusion some non-aromatic peak of the ALP was completely disappeared in the proton NMR spectra of ALP, leave strong evidence of inclusion complexation [33].
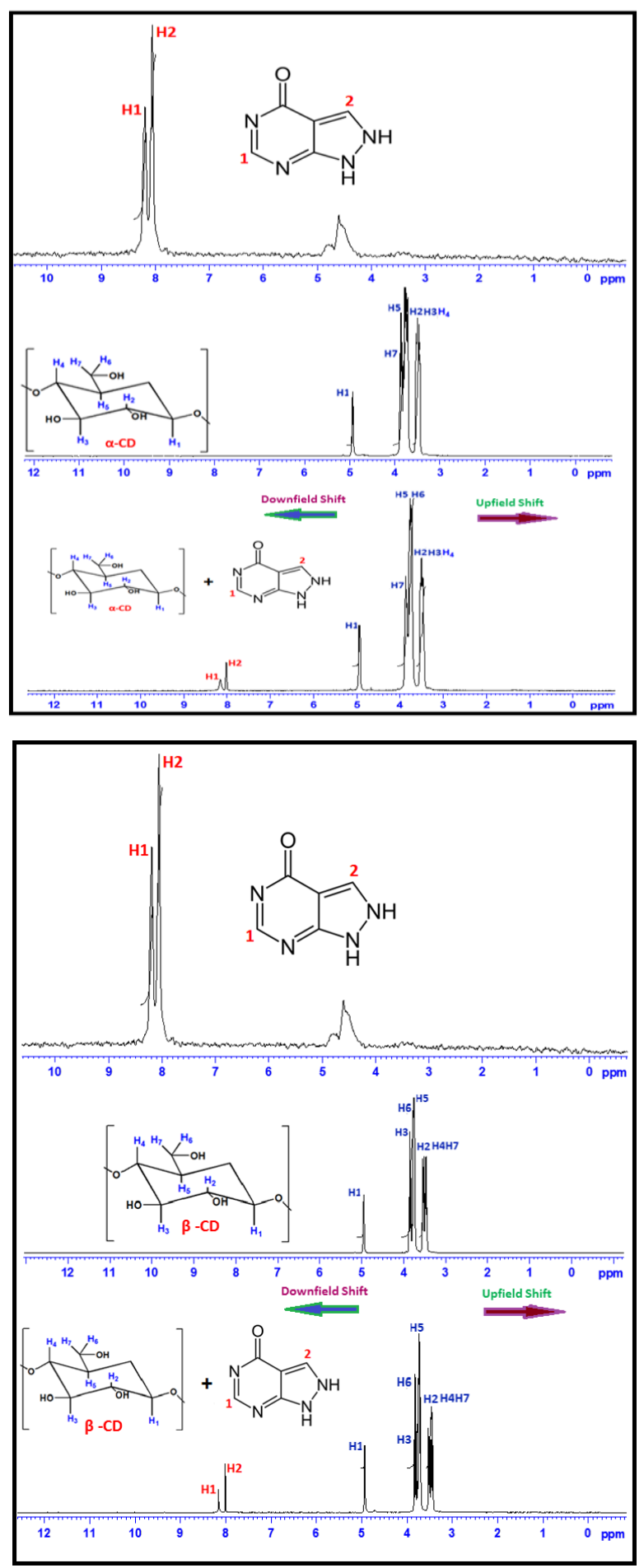


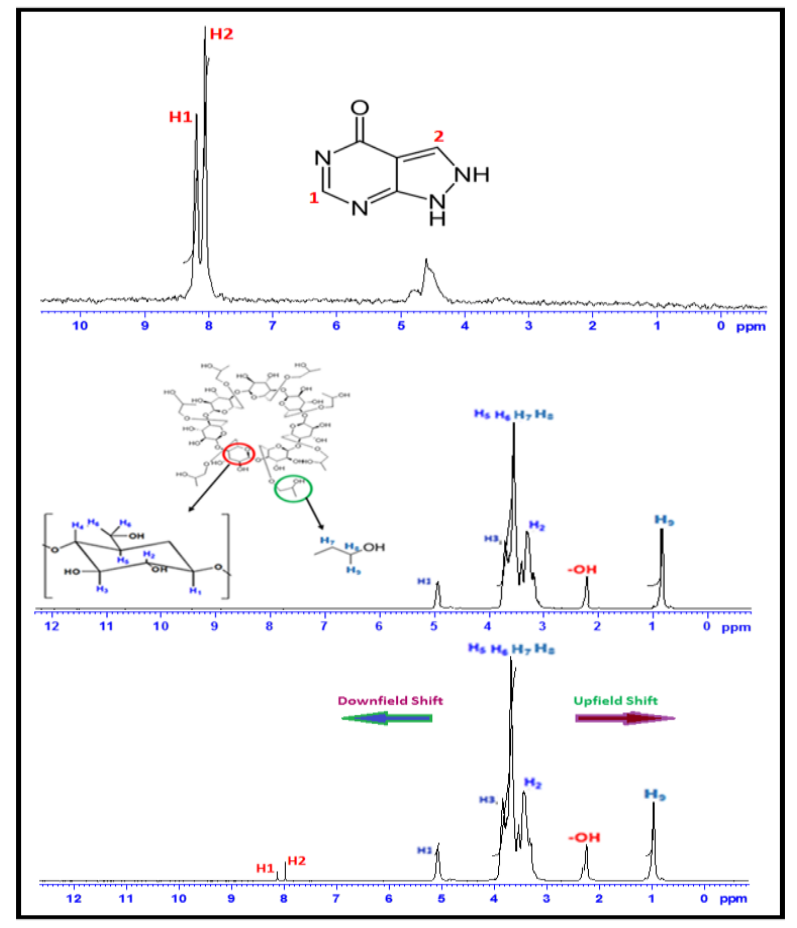

Fig. $8{ }^{1} \mathrm{H}-\mathrm{NMR}$ spectra of the pure compounds and inclusion complexes with a) [ALP], b) $[\mathrm{ALP}]+\alpha-\mathrm{CD}, \mathrm{c})[\mathrm{ALP}]+\beta-\mathrm{CD}$ and d) $[\mathrm{ALP}]+\mathrm{HP}-\beta-\mathrm{CD})$ at $298.15 \mathrm{~K}\left(400 \mathrm{MHz}, \mathrm{D}_{2} \mathrm{O}\right)$

\subsection{D-ROESY Spectroscopy}

The principle of '2D ROESY' is the interaction of protons which are present in close proximity of $0.4 \mathrm{~nm}$ range to each other to produce NMR cross peak. In our study, we investigated the inclusion of ALP inside the $\alpha$ $C D, \beta-C D$, and HP- $\beta$-CD hydrophobic cavity. NMR study was carried out in $\mathrm{D}_{2} \mathrm{O}$. It is clear $\mathrm{H}-3$ and $\mathrm{H}-5$ protons of CDs are present inside the cavity and hence if inclusion happens, there should be presence of such close proximity of $0.4 \mathrm{~nm}$ of the ALP protons with $\mathrm{H}-3$ and $\mathrm{H}-5$ protons of CD which can produce rotating-frame nuclear overhauser effect spectroscopy (ROESY) to give cross peaks.

In the Figs. 9a-c, there is the presence of cross peaks of $\mathrm{H} 3$ and $\mathrm{H} 5$ protons of $\beta-\mathrm{CD}$ with $\mathrm{H}-3$ and H-5 protons of the aromatic ring and H-4' protons of [ALP]; with the $\mathrm{H} 3$ and $\mathrm{H} 5$ protons of $\alpha-\mathrm{CD}$ and $\mathrm{H}-1^{\prime}, \mathrm{H}-1$ " and $\mathrm{H}-4$ 'of $[\mathrm{ALP}]$ and negligible cross peaks in HP- $\beta-C D$. In the dynamic process of inclusion, the cross peaks are generated due to insertion of the pyrazole part of the ALP as well as the aromatic ring of the ALP but it is sterically unfavourable. Hence in some cases benzylic part and in some cases pyrazole enters inside the cavity. This signifies inclusion phenomena of the said ALP into CD cavity [34]

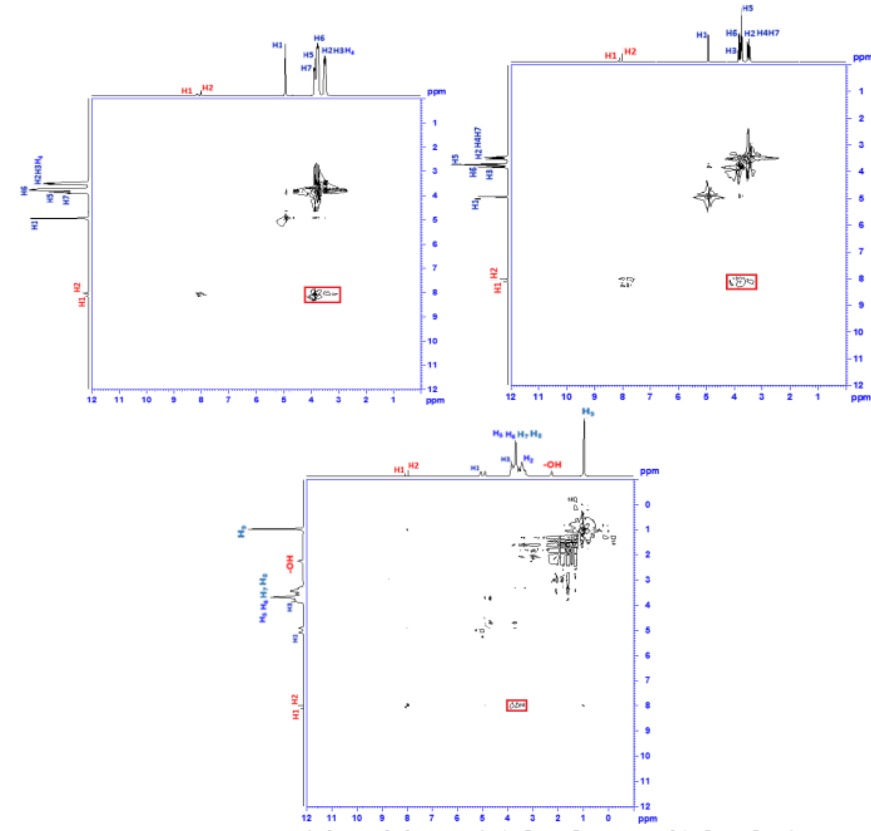

Fig. 9 2D ROESY spectra of the solid ICs of a) $[A L P]+\alpha-C D$, b) $[A L P]+\beta-C D$ and c) $[\mathrm{ALP}]+\mathrm{HP}-\beta-\mathrm{CD}$ ) in $\mathrm{D}_{2} \mathrm{O}$ (Cross correlations are indicated by red circles)

\subsection{SEM}

A very illustrious technique for analyzing the surface texture and particle size of solid materials. The exterior surface morphological structures of $(\alpha-, \beta-$, HP- $\beta$-) CD and solid IC (ALP: $\alpha-C D, A L P: \beta-C D, A L P$ : HP- $\beta$-CD) are shown in respectively. From Figs. 10a-c, it is obvious that morphological structures of each are totally different from each other. Moreover, as the complexation by $\alpha-, \beta$ - and HP- $\beta$-CD can be viewed distinctly. This provides clear evidence that [ALP] fits adequately into the hydrophobic cavity of CD's to figure solid IC with different morphology. [35].
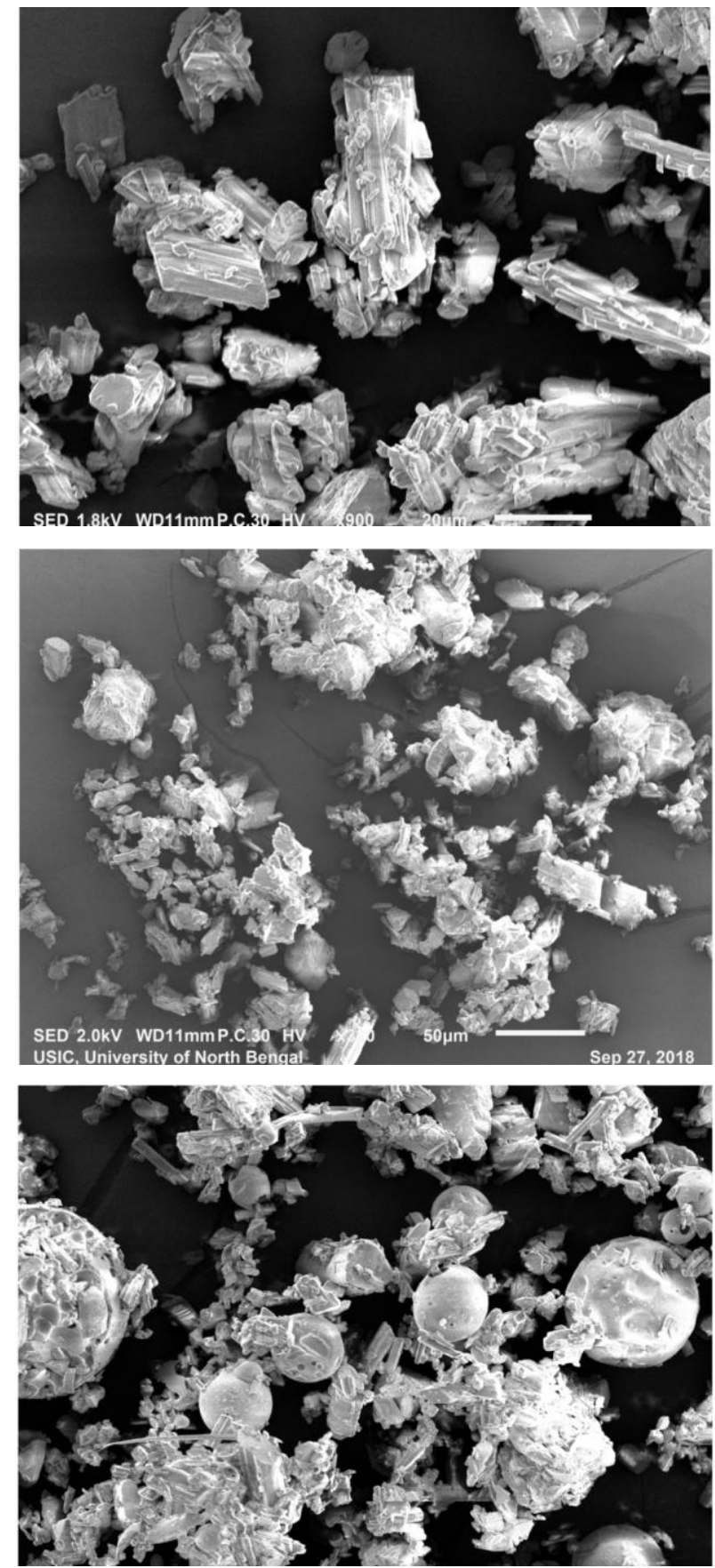

Fig. 10 SEM showing morphologic study of a) $[A L P]+\alpha-C D$, b) $[A L P]+\beta-C D$ and c) $[\mathrm{ALP}]+\mathrm{HP}-\beta-\mathrm{CD})$ in $(1: 1 \mathrm{M}$ ratio) of inclusion complex

\subsection{PXRD - Powdered X-Ray Diffraction Spectroscopy}

X-ray diffraction (XRD analysis or XRPD analysis) is an exclusive method in determination of crystallinity of a compound. It is primarily used for crystalline material of different polymorphic forms. Distinguishing among amorphous and crystalline material, quantification of the percent crystallinity of a sample is the mandatory criteria. We find (Figs. 11a-d) the crystallinity changes in the complexes by definite angles [36]. 

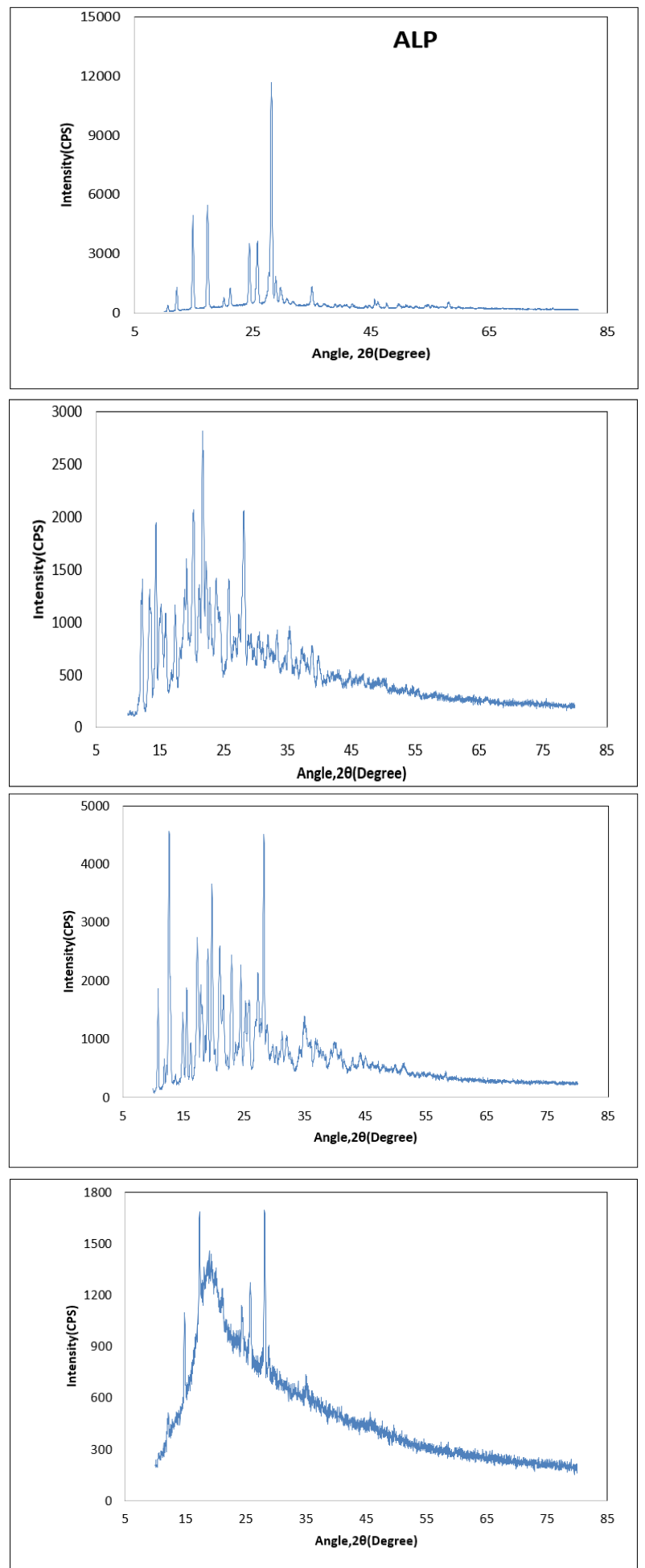

Fig. 11 Powder X-ray diffraction pattern of a) [ALP], b) [ALP] $+\alpha-C D$, c) $[A L P]+\beta-C D$ and d) $[A L P]+H P-\beta-C D)$

\subsection{ESI-MS Analysis}

The 'ESI-mass spectrometric analysis' were additionally used to recognize the formation of IC synthesized by procedure described above in the solid state of experimental procedure and have been shown in Figs. 12a-c. Observation of peaks have been put, which verifies that in each cases the desired IC's have been formed in solid state and stoichiometric ratio of (host: guest) is (1: 1). The 'Positive electrospray ionization mass spectrometry' [ESI-MS] is enormously important process that has been used to examine host guest complexation with the two studied cyclodextrins. Mass spectrums of (1:1) stoichiometries of [ $\alpha$-CD: $\{$ ALP $\}],[\beta$ $:\{A L P\}$ and [HP- $\beta-C D:\{A L P\}]$ systems are evaluated by [ESI-MS] represents every preferred mass that one can expect. These experimental facts of the chosen [[ALP]/ $\alpha-\mathrm{CD}],[[\mathrm{ALP}] / \beta-\mathrm{CD}]$ and $[[\mathrm{ALP}] / \mathrm{HP}-\beta-\mathrm{CD}]$ complexes recommended that the $[[\mathrm{ALP}]+$ cation] simultaneously inserted in cyclodextrin's hollow space with (1:1) stoichiometry [33]. https://doi.org/10.30799/jacs.205.19050105
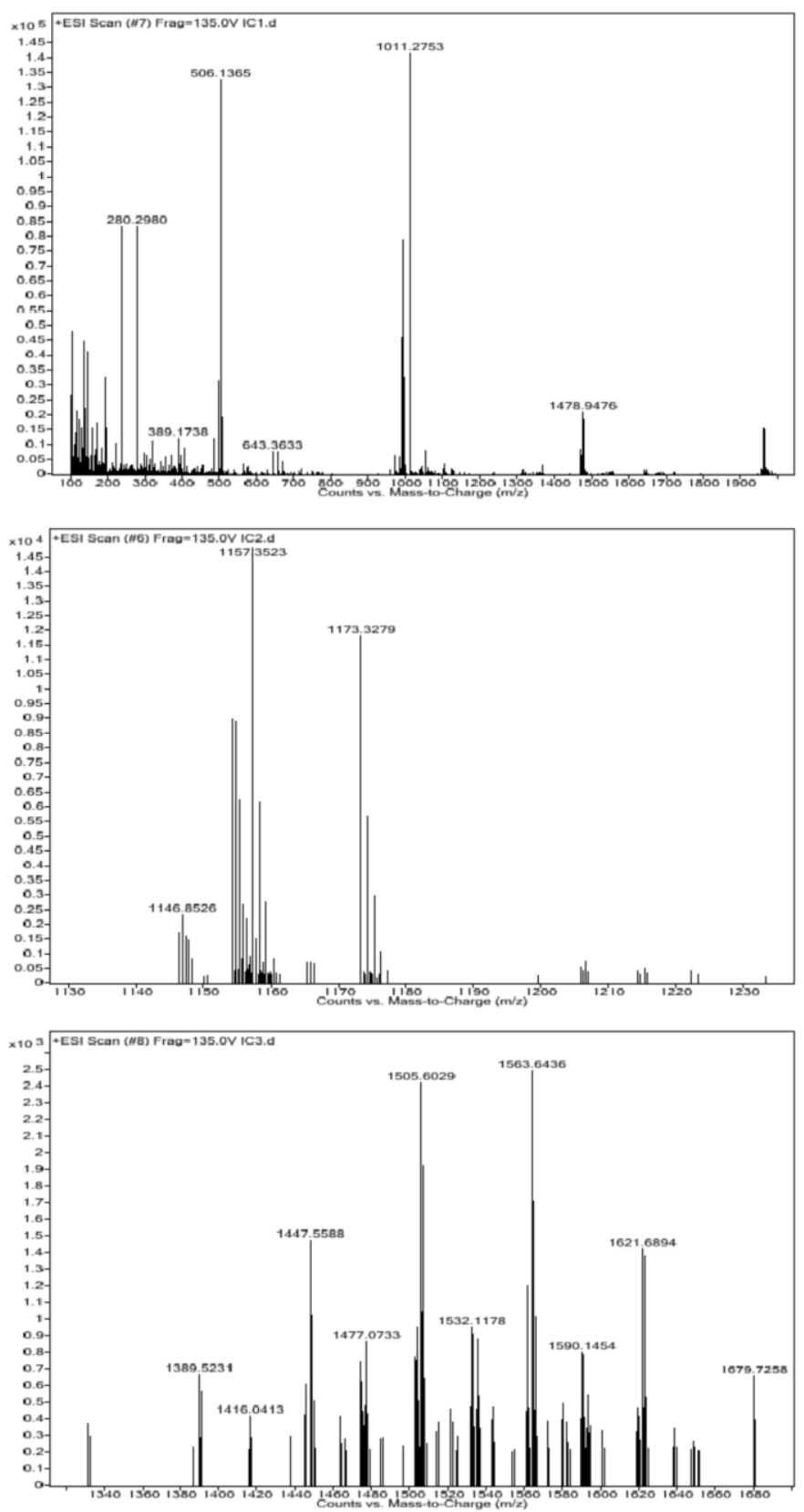

Fig. 12 ESI mass spectra of a) $[A L P]+\alpha-C D, b)[A L P]+\beta-C D$ and c) $[A L P]+H P-\beta-C D)$ inclusion complex

\subsection{Biological Activity}

ALP itself is non-toxic to cut micro flora. No zone of inhibition, in case of both the gram-positive and gram-negative organisms. There was no growth inhibition compared to control. These results recommend that ICs $(\mathrm{IC} 1=[\mathrm{ALP}+\alpha-\mathrm{CD}], \mathrm{IC} 2=[\mathrm{ALP}+\beta-\mathrm{CD}], \mathrm{IC} 3=[\mathrm{ALP}+\mathrm{HP}-\beta-\mathrm{CD}]$ doesn't have any antimicrobial activity shown in Figs. 13a-b. So, it is nontoxic for the cells experiment based on the sensitivity towards cut micro flora. There is no effect on cut-microbes- host interaction [37].

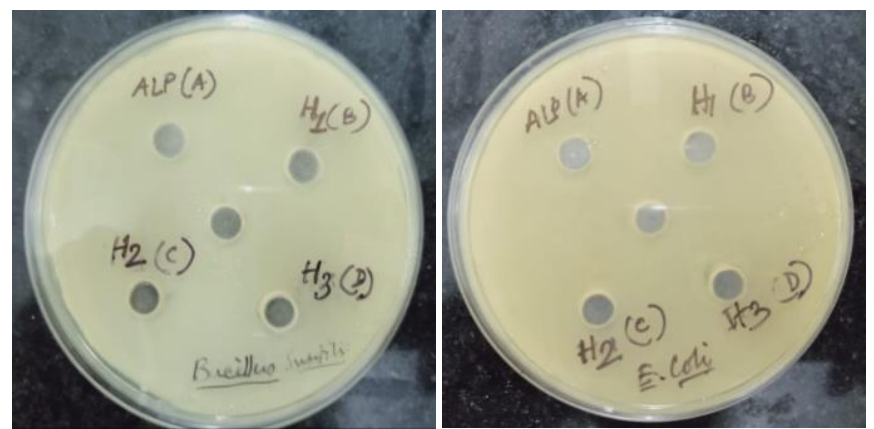

Fig. 13 Antimicrobial activity analysis on ALP on a) gram-positive B. subtilis and b) gram-negative $E$. coli. No zone of inhibition was observed with IC1, IC2, and IC3. Double distilled water was taken as the control 


\section{Conclusion}

Allopurinol sketch host-guest inclusion complexes together with $(\alpha$-, $\beta$-, HP- $\beta$-) CD win the (1:1) stoichiometry which is recognized by UV, NMR, steady state fluorescence, SEM, HRMS imply that the selected guest (ALP) molecule, shaped IC's with nano hydrophobic core of efficiency. As a result, the present work adjoins a new dimension in the diversified field of existing science of controlled release of allopurinol through appropriate host molecules like ( $\alpha-, \beta-$, HP- $\beta-)$ CD.

\section{Acknowledgement}

The authors are thankful to Special Assistance Scheme, Department of Chemistry, and University of North Bengal under UGC, New Delhi (No. 540/27/DRS/2007, SAP-1) for financial provisions and instrumental services. Prof. M. N. Roy is also highly obliged to the UGC, New Delhi, Government of India for being awarded "One-time Grant under Basic Scientific Research" using the Grant-in-Aid No. F.4-10/2010 (BSR) concerning his dynamic service for augmenting of research facilities to advance the research works. We are also thankful to SAIF, North Eastern Hill University, for the NMR, ESI-MS, and PXRD spectroscopic study.

\section{References}

[1] V.Q. Scheele, Examen Chemicum Calculi Urinari, Opuscula 11, In: Nucleic Acids, Chemical Catalog Co New York, NY, 1776, p.73.

[2] S.R.J. Maxwell, H. Thomason, D. Sandler, C. Leguen, M.A. Baxter, et al., Antioxidant status in patients with uncomplicated insulin-dependent and noninsulin-dependent diabetes mellitus, Eur. J. Clin. Investigat. 27(6) (1997) 484490.

[3] L.X. Chen, H.R. Schumacher, Gout: An evidence-based review, J. Clin. Rheumato. 14 (2008) 55-62.

[4] K.G. Lawrence, A. Saco, Preferential solvation of ions in mixed solvents, J. Chem. Soc. Faraday Trans. 79 (1983) 615-619.

[5] R. Pogue, G. Atkinson, Solution thermodynamics of first-row transition elements, Apparent molal volumes of nickel dichloride, nickel diperchlorate, cupric chloride and cupric perchlorate from 15 to $55^{\circ} \mathrm{C}$, J. Chem. Eng. Data. 33 (1988) 370-376.

[6] Y. Marcus, G. Hefter, T.S. Pang, Ionic partial molar volumes in non-aqueous solvents, J. Chem. Soc. Faraday Trans. 90 (1994) 1899-1903.

[7] G. Moumouzias, D.K. Panopoulas, G. Ritzoulis, Excess properties of binary liquid system propylene carbonate + acetonitrile, J. Chem. Eng. Dat, 36 (1991) 20-23.

[8] K.S. Lisa., J.L.O'Donnell, M. Zhang, J. James, C. Frampton, et al., Using allopurinol above the dose based on creatinine clearance is effective and safe in patients with chronic gout, including those with renal impairment, Arthritis Rheum. 63(2011) 412-421.

[9] N.S. Rajendra, Jacob George, J.J. F. Belch, C.C. Lang, A.D. Struthers, Mechanistic insights into the therapeutic use of high-dose allopurinol in angina pectoris, J. American Col. Cardiol. 58 (2011) 8-ENDPAGE.

[10] D. Tousoulisa, I. Andreoua, M. Tsiatasa, A. Milioua, C. Tentolourisa, et al., The effect of high vs. low carbohydrate diets on distances covered in soccer, Atherosclerosis 214 (2011)151-157.

[11] A. Noman, D.S.C. Ang, S. Ogston, C.C. Lang, A.D Struthers, Effect of high-dose allopurinol on exercise in patients with chronic stable angina: a randomised, placebo-controlled crossover trial, Lancet 375 (2011) 2161-2167.

[12] E.S. Ryu, M.J. Kim, H.S. Shin, Y.H. Jang, H.S. Choi, et al., Uric acid-induced phenotypic transition of renal tubular cells as a novel mechanism of chronic kidney disease, Am. J. Physiol. Renal. Physiol. 304 (2013) 471-480.

[13] Y.C. Chou, J.C. Kuan, T. Yang, W.Y. Chou, P.C. Hsieh, et al., Elevated uric acid level as a significant predictor of chronic kidney disease: a cohort study with repeated measurements, Italian Soc. Nephrol. J. Nephrol. 28 (2014) 457-462.
[14] A.M. El Nahas, A.K. Bello, Chronic kidney disease: the global challenge, Lancet 365 (2005) 331-340.

[15] H.W. Kuo, S.S. Tsai, S.S. Tiao, C.Y. Yang, Epidemiological features of CKD in Taiwan, Am. J. Kidney Dis. 49 (2007) 46-55.

[16] D.H. Kang, W. Chen, Uric acid and chronic kidney disease: new understanding of an old problem, Semin. Nephrol. 31 (2011) 447-452.

[17] R.J. Johnson, T. Nakaqawa, D. Jalal, L.G. Sanchez-Lozada, D.H. Kang, E. Ritz, Uric acid and chronic kidney disease: which is chasing which?, Nephrol. Dial. Transplant 28 (2013)2221-2228.

[18] G.R.A. Eleamen, S.C. Da Costa, R.G. Lima-Neto, R.P. Neves, L.A. Rolim, et al., Improvement of solubility and antifungal activity of a new aminothiophene derivative by complexation with 2-hydroxypropyl- $\beta$-cyclodextrin, J. Braz Chem. Soc. 28 (2017) 116-125.

[19] M. Malanga, J. Szeman, E. Fenyvesi, Back to the Future, J. Pharm. Sci. 105 (2016) 2921-2931.

[20] Tetsumi Irie, Kaneto Uekama, Pharmaceutical applications of cyclodextrins. iii. toxicological issues and safety evaluation, J. Pharm. Sci. 86 (1997) 147-162.

[21] V.J. Stella, Q. He, Cyclodextrins, Toxicol. Pathol. 36 (2008) 30-42.

[22] Y. Murata, K. Kofuji, S. Nakano, R. Kamaguchi, Cyclodextrin-modified film dosage forms for oral candidiasis treatment, Pharmacol. Pharm. 6 (2015) 247 253.

[23] W. Vizzardi, C. Sagarriga Visconti, L. Pedrotti, N. Marzano, et al., Beta cyclodextrin (nimesulide-betadex) versus nimesulide in the treatment of pain after arthroscopic surgery, Curr. Therapeutic Res. 59 (1998) 162-171.

[24] K. Uekama, F. Hirayama, T. Irie, Cyclodextrin drug carrier systems, Chem. Rev. 98 (1998) 2045-2076.

[25] V. Jimenez, J.B. Alderete, E.J. Delgado, J. Belmar, J. Gavın, On the complexation of allopurinol with $\beta$-cyclodextrin, Struct Chem. 17 (2006) 217-223.

[26] A. Dutta, B.K. Barman, B. Mahato, H. Rahaman, M.N. Roy, Study to explore complexation of crown ether with antidepressant drug prevalent in aqueous system by physicochemical contrivance, Ind. J. Adv. Chem. Sci. 6(3) (2018) 171177.

[27] A.S.I. Amer, A.M.M. Alazaly, A.A. Abdel-Shafi, Solvatochromism of 1-naphthol4-sulfonate photoacid and its encapsulation in cyclodextrin derivatives, J. Photochem. Photobiol. A: Chem. 369 (2019) 202-211.

[28] M. Bartolotta, M.T. Buthelezi, Molecular polarity effect on the association constant of cyclodextrin-pyrimidine nucleobases in water, J. Photochem. Photobiol. A: Chem. 371 (2019) 382-386.

[29] I. Yakavets, H.P. Lassalle, I. Yankovskya, F. Ingrossod, A. Monarid, et al., Evaluation of temoporfin affinity to $\beta$-cyclodextrins assuming self-aggregation, J. Photochem. Photobiol. A: Chem. 367 (2018) 13-21.

[30] L. Yuan, S. Li, D. Huo, W. Zhou, X. Wang, et al., Studies on the preparation and photostability of avobenzone and (2-hydroxy)propyl- $\beta$-cyclodextrin inclusion complex, J. Photochem. Photobiol. A: Chem. 369 (2019) 174-180.

[31] X. Zhou, J.F. Liang, A fluorescence spectroscopy approach for fast determination of $\beta$-cyclodextrin-guest binding constants, J. Photochem. Photobiol. A: Chem. 349 (2017) 124-128.

[32] B.K. Barman, A. Dutta, M.N. Roy, Sustenance of inclusion complexes of ionic liquid with cyclic oligosaccharide molecules in liquid and solid phases by diverse approaches, Chem. Select 3 (2018) 7527 - 7534.

[33] B. Rajbanshi, S. Saha, K. Das, B.K. Barman, S. Sengupta, et al., Study to probe subsistence of host-guest inclusion complexes of $\alpha$ and $\beta$-cyclodextrins with biologically potent drugs for safety regulatory dischargement, Sci. Rep. 8 (2018) 13031.

[34] U. Kemelbekov, Y. Luo, Z. Orynbekova, IR, UV and NMR studies of $\beta$ cyclodextrin inclusion complexes of kazcaine and prosidol bases, J. Incl. Phenom. Macrocycl. Chem. 69 (2011) 181-190.

[35] S. Saha, A. Roy, K. Roy, M.N. Roy, Study to explore the mechanism to form inclusion complexes of $\beta$-cyclodextrin with vitamin molecules, Sci. Rep. 6 (2017) 35764.

[36] H. Bera, S. Chekuri, S. Sarkar, S. Kumar, N.B. Muvva, et al., Novel pimozide- $\beta$ cyclodextrin-polyvinylpyrrolidone inclusion complexes for Tourette syndrome treatment, J. Mol. Liq. 215 (2016) 135-143.

[37] T.A. Andrade, Physico-chemical characterization and antibacterial activity of inclusion complexes of Hyptis martiusii Benth essential oil in $\beta$-cyclodextrin, Biomed. Pharmacother. 89 (2017) 201-207. 